\title{
SYNTHESIS OF 2-AMINO-3-PHENYLPROPAN-1-OL COMPOUNDS FROM BAYLIS-HILLMAN DERIVATIVES, CARBON NANOTUBE, KINETIC, LIFETIME AND BIOLOGICAL STUDIES
}

\author{
P. Senthilkumar ${ }^{1}$, V. Srinivas ${ }^{1}$ and M.N. Sivakumar ${ }^{2}$,* \\ ${ }^{1}$ Department of Mechanical Engineering, AMET University, \\ Chennai-603 112, Tamil Nadu, India \\ ${ }^{2}$ Department of Chemistry, AMET University Chennai 603 112, Tamil Nadu, India \\ *E-mail : nitrosiva@gmail.com
}

\begin{abstract}
We have successfully synthesized a novel class 2-amino-3-phenylpropane-1-ol by carbon nanotube method reaction for the first time. We have also carried out the iron acidic acid reduction reaction on Baylis-Hillman adducts to synthesize an array of novel 2-amino-3-phenylpropane-1-ol from nitroolefin derivatives reaction with good yields. Amine compounds carried out kinetic and Biological Studies.

Keywords: Baylis-Hillman adducts, Carbon nanotube, Iron acidic acid, (E)-2-nitro-3-phenylprop-2- en-1-ol, 2amino-3-phenylpropane-1-ol.

(c) RASĀYAN. All rights reserved
\end{abstract}

\section{INTRODUCTION}

The Baylis-Hillman reaction, in the current day version, is an atom-economic carbon-carbon bondforming reaction between the $\alpha$-position of the activated alkenes and carbon electrophiles under the influence of a catalyst or catalytic system given that diverse classes of densely functionalized molecules, which are usually referred to as the Baylis-Hillman adducts

(Scheme-1). ${ }^{1-6}$

Most of the Baylis-Hillman reactions are catalyzed by organic compounds like tertiary amines and alkyl(aryl) phosphines, and thus these reactions are referred to as the "organocatalysis reactions". The Baylis-Hillman reaction is a three-component carbon-carbon bond-forming reaction [activated alkenes (alkynes), electrophiles, and catalysts] as long as a molecule with diverse functionalities. This reaction creates a chiral center in the case of a prochiral electrophile thus contribution challenges and opportunities for increasing its asymmetric version. Since the Baylis-Hillman adducts are compactly functionalized molecules and due to the closeness of functional groups, these adducts are extremely useful as synthons in a number of synthetic processes and also in the synthesis of interesting natural and unnatural products of medicinal applications.

If the substrate contains both the activated alkene and electrophile components in appropriate positions, there is the option of developing an intramolecular version of this reaction leading to the synthesis of carbocyclic or heterocyclic compounds, and thus this reaction offers challenges to design and synthesize of various substrates that can be transferred into diverse classes of carbocyclic and heterocyclic compounds. Many variations of parameters present in this reaction, in fact, generate wide spectra of mechanistic pathways, thereby making understanding the mechanism of this reaction an intellectual challenge.

The Baylis-Hillman adducts have been successfully utilized as synthons in several named reactions such as Heck reaction, Diels-Alder reaction, Aldol condensation, Claisen rearrangement, Friedel-Crafts reation $^{7-10}$ etc. The FriedelCraftsreaction is one of the most widely used reactions in organic chemistry whose applications in academic as well as industrial fields have been well documented. ${ }^{11-17}$ 
RASĀYAN J. Chem.

Vol. 11 | No. 1 |175-180 | January - March | 2018

\section{EXPERIMENTAL}

To execute our idea we premeditated to synthesize various Baylis-Hillman adducts (3a) by the treatment of (E)-(2-nitrovinyl)arenes (1) with paraformaldehyde (2) using imidazole and anthranilic acid as a catalytic system according to Scheme1. The compound 3a was characterized by IR, 1H \& 13C NMR spectroscopy, mass spectrometry and elemental analysis (Scheme-1).

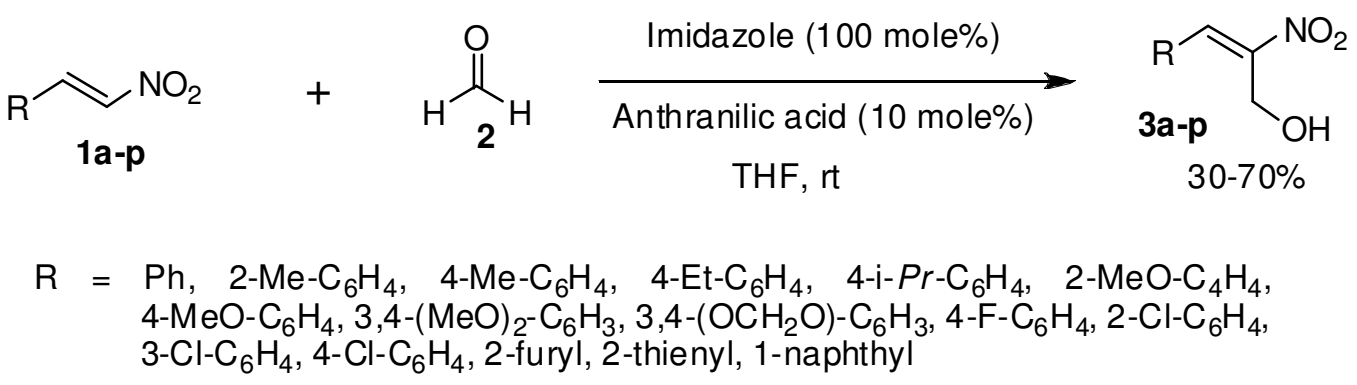

Scheme-1

The 1H NMR spectrum of compound 3a showed a singlet for hydroxyl proton at $\delta 2.61$ and doublet was observed for $\mathrm{O}-\mathrm{CH} 2$ protons at $\delta 4.71$. The aromatic protons appeared as multiplet in the region of $\delta 7.48$ 7.58. The olefinic proton observed as a singlet at $\delta 8.22$.

To implement our idea, first we have chosen the (E)-2-nitro-3-phenylprop-2-en-1-ol (3a) derived from nitrostyrene and formaldehyde as starting material for reduction reaction. The best results were obtained when the addition of a catalytic amount of Fe and acidic acid solution (excess) (4) at reflux temperature successfully led to the most wanted product 2-amino-3-phenylpropane-1-ol. (5) in 82\% yield after column chromatography purification. The compound 5a was characterized by $\mathrm{IR},{ }^{1} \mathrm{H},{ }^{13} \mathrm{C}$ NMR, mass and elemental analyses (Scheme-2).

$\mathrm{Fe}, \mathrm{CH}_{3} \mathrm{COOH}, \mathrm{CNT}$
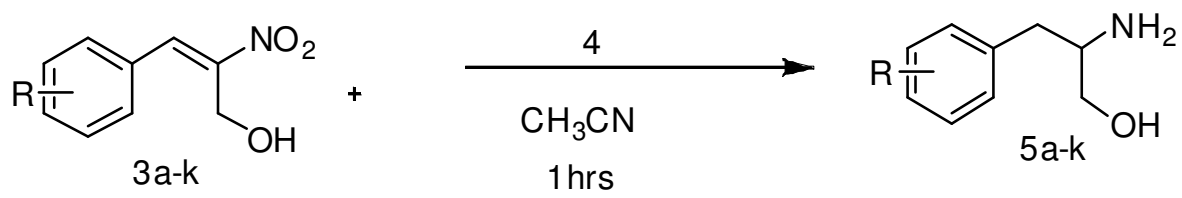

$$
\begin{aligned}
\mathrm{R}= & \text { 2-Me, 4-Me, 4-Et, 4- }-\mathrm{-}-\mathrm{Pr}, 4-\mathrm{OMe}, 3,4-\mathrm{di}-\mathrm{OMe}, \\
& \text { 3,4-O } \mathrm{OCH}_{2} \mathrm{O}-\text {, 4- } \mathrm{F}, 2-\mathrm{Cl}, 3-\mathrm{Cl}, 4-\mathrm{Cl}
\end{aligned}
$$

Scheme-2

Confident by this result, we utilized a variety of (E)-2-nitro-3-arylprop-2-en-1-ols(3b-k) as starting materials for the synthesis of (E)-2-nitro-1,3-diarylprop-1-enes. Treatment of the compounds with Fe and acidic acid successfully led to the desired chiral amine compounds (5b-k) in $74-80 \%$ yields. The ${ }^{1} \mathrm{H}$ NMR spectrum of compound 5a showed a doublet of the doublet doublet for $\mathrm{O}-\mathrm{CH}_{2}$ protons at $\delta 3.15$. The $\mathrm{CH}-\mathrm{CH}_{2}$ protons appear as a multiplet at $\delta$ 2.73-3.06 and $\mathrm{CH}_{2} \mathrm{CH}$ - proton appears as a multiplet at $\delta$ 2.83-3.21. The aromatic protons appeared as multiplet in the region of $\delta 7.25-7.48$ and the $\mathrm{OH}$ proton appeared as a singlet at $\delta 3.59$. The $\mathrm{NH}_{2}$ appear as a singlet at $\delta 5.23$ which confirms the $E$-geometry.

Typical experimental procedure for the synthesis of $(E)$-(2-nitroprop-1-ene-1,3-diyl)dibenzene (5a) To a stirred solution of (E)-2-nitro-3-phenylprop-2-en-1-ol (5a) $(0.48 \mathrm{~g}, 2 \mathrm{mmol})$ in acidic acid (10 ml), and Iron powder (Excesses) $(0.5 \mathrm{ml})$ was added at reflux temperature. The reaction mixture was stirred at reflux temperature for about $1 \mathrm{~h}$. After the completion of reaction (confirmed by TLC analysis), the mixture was poured into water and the aqueous layer was extracted with ethyl acetate $(3 \times 10 \mathrm{ml})$. The 
combined organic layer was washed with brine $(20 \mathrm{ml})$, and dried over anhydrous $\mathrm{Na}_{2} \mathrm{SO}_{4}$. The crude product thus obtained was purified by column chromatography ( $2 \%$, EtOAc / hexanes) to provide the desired compound $\mathbf{5 a}$ in $82 \%(0.23 \mathrm{~g})$ yield, as a yellow oil.

IR (KBr): 2346, 1353, $764 \mathrm{~cm}^{-1},{ }^{1} \mathrm{H}$ NMR $\left(\mathrm{CDCl}_{3}, 300 \mathrm{MHz}\right): \delta 2.73-3.06(\mathrm{~m}, 1 \mathrm{H}), 3.15 .(\mathrm{dd}, 2 \mathrm{H}), 2.83-$ $3.21(\mathrm{~m}, 2 \mathrm{H}), 3.59(\mathrm{bs}, 1 \mathrm{H}), 5.23(\mathrm{bs}, 2 \mathrm{H}), 7.25-7.48(\mathrm{~m}, 5 \mathrm{H}){ }^{13} \mathrm{CNMR}\left(\mathrm{CDCl}_{3}, 75 \mathrm{MHz}\right): \delta 35.29,47.03$, $65.69,128.98,129.17,129.72,130.47,143.76$.

MS (m/z): $151\left(\mathrm{M}^{+}+1\right)$.

Elemental Analysis for $\mathrm{C}_{9} \mathrm{H}_{13} \mathrm{NO}$

Calculated: C, 71.49; H, 8.67; N, 9.26.

Found: C, 71.47; H, 8.68; N, 9.25

\section{Lifetime Measurement of nitro compounds}

\section{RESULTS AND DISCUSSION}

Time connected Single Photon Counting (TCSPC) measurement of fluorescence lifetime has simplified the use of the time domain method. This fitting evidently shows that the compound is well fitted with tri exponential and bi exponential fitting. ${ }^{22}$ The emission spectra and decay time measurements for the $5 \mathrm{a}$ compound allowed the identification of the highest triplet state shown in Fig.-1. 5a having high lifetime value compared to another mononuclear compound. The order of the lifetime is increased.

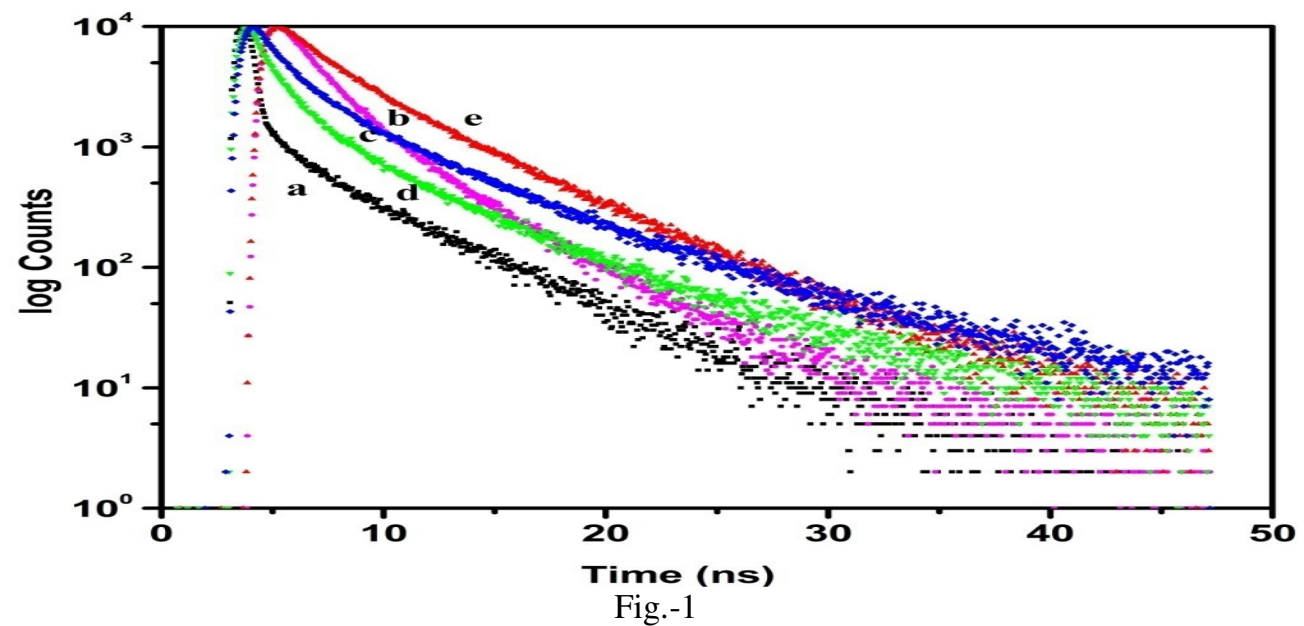

Table-1: Lifetime measurement value of nitro compound

\begin{tabular}{c|c|c|c|c|c|c|c}
\hline Compound & $\tau_{1} / \mathrm{ns}$ & $\alpha_{1}(\%)$ & $\tau_{2} / \mathrm{ns}$ & $\alpha_{2}(\%)$ & $\tau_{3} / \mathrm{ns}$ & $\alpha_{3}(\%)$ & $\chi^{2}$ \\
\hline $5 \mathrm{a}$ & 0.952 & 22.86 & 1.500 & 32.11 & 6.750 & 45.03 & 1.079 \\
\hline $5 \mathrm{c}$ & 0.322 & 14.03 & 1.370 & 41.69 & 5.450 & 44.29 & 1.105 \\
\hline $5 \mathrm{~d}$ & 1.640 & 28.41 & 5.080 & 71.59 & ----- & ------ & 1.144 \\
\hline $5 \mathrm{e}$ & 1.330 & 50.82 & ------ & ----- & 3.910 & 49.18 & 1.114 \\
\hline $5 \mathrm{~h}$ & 0.132 & 55.83 & 2.750 & 11.06 & 5.350 & 33.11 & 1.176 \\
\hline
\end{tabular}

\section{Kinetic studies of Hydroxy amino compound}

The catalytic activity of the Hydroxy amino compound was determined spectrophotometrically by monitoring the increase in the characteristic absorbance of the amine anion at $420 \mathrm{~nm}$ over the time in dimethylformamide at $25^{\circ} \mathrm{C}$. For this purpose, $10^{-3} \mathrm{~mol} \mathrm{dm}^{-3}$ solutions of the amino compound were treated with 100 equivalents of 4-nitrophenyl in the presence of air.The course of the reaction was followed at $420 \mathrm{~nm}$ for nearly $45 \mathrm{~min}$ at regular time intervals. The slope was determined by the method of initial rates by monitoring the growth of the $420 \mathrm{~nm}$ band of the product 4-nitro anion. A linear relationship between all the compound shows a first-order dependence on the compound concentration for the systems.Plots of $\log (\mathrm{A} \alpha / \mathrm{A} \alpha-\mathrm{At})$ versus time for hydrolysis of amine activity of the compound are obtained and shown in Fig.-2. 


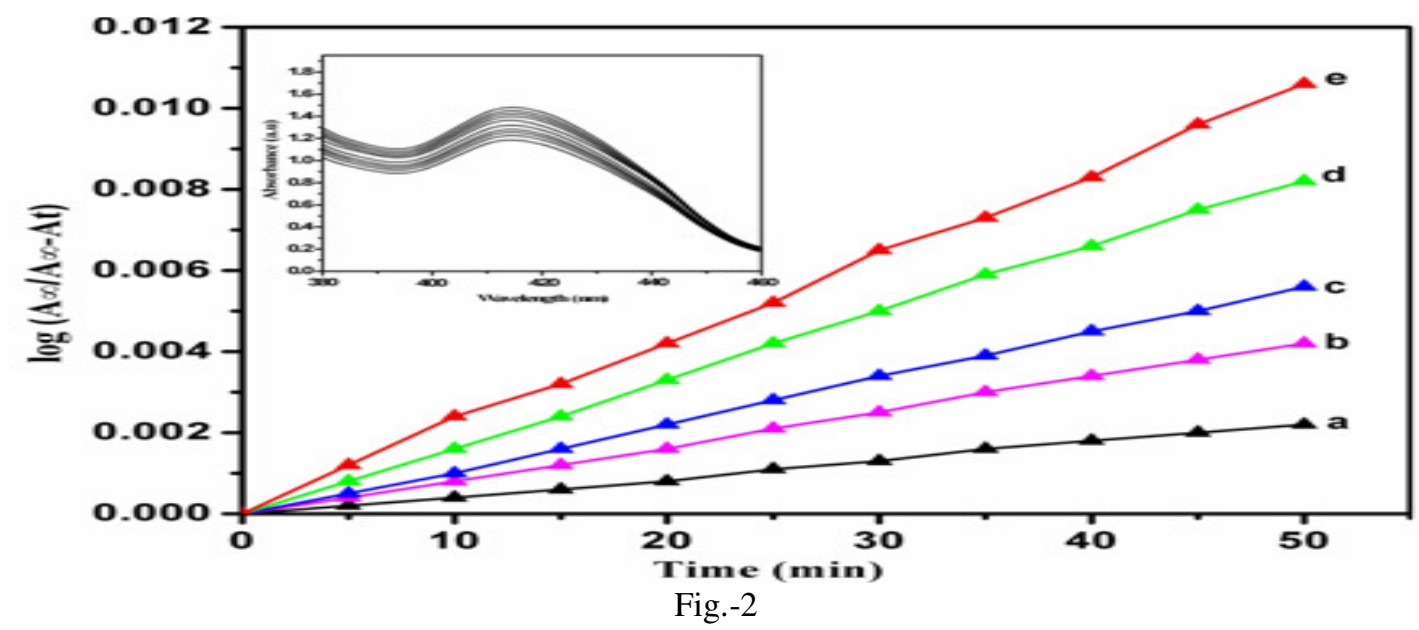

\section{Microorganisms}

The test bacterial strains Escherichia coli, Klebsiella sp, Candida albicans, Salmonella typhi, and Staphylococcus aureus were obtained from the Department of Microbiology, SRM University, Chennai, Tamil Nadu was isolated clinically. The test organisms were sub-cultured at $37^{\circ} \mathrm{C}$ and maintained on nutrient agar media.

\section{Anti-Microbial activity, Disc Diffusion Method}

The bacterial inoculum was uniformly spread using sterile glass rod on a sterile Petri dish containing Nutrient Agar. Five concentrations of 25, 50, 75, 100 and $125 \mu \mathrm{M}$ of pure substances were prepared in DMSO. The test substances of $50 \mu \mathrm{L}$ were added to each of the 5 wells $(7 \mathrm{~mm}$ diameter holes cut in the agar gel, $20 \mathrm{~mm}$ apart from one another). The systems were incubated for $24 \mathrm{~h}$ at $36{ }^{\circ} \mathrm{C} \pm 1{ }^{\circ} \mathrm{C}$, under aerobic conditions. After incubation, confluent bacterial growth was observed. Inhibition of the bacterial growth was measured in $\mathrm{mm}$. Tests were performed in duplicate, whose minimum inhibitory concentration (MIC) values are provided in centimeters $(\mathrm{CM})$ in diameter.

Antimicrobial activity of synthesized compound against five tested microorganisms has been studied. As per the recorded data all the mono nuclear compounds showed different effects against the different organisms showing highest activity against Klebsiella sp and at the concentration of $125 \mu \mathrm{M}$. Compound 5a has the highest antimicrobial activity against all the organisms, MIC of Nutrient agar plates photos are given as Figures-3 and 4. In contrast, $\mathbf{5 h}$ showed the lowest activity. This difference might be due to the different structure of chemical compounds and activity of side chains i.e. the difference in the binding site of the amine with the molecules data are given in the Tables- 1 to 5.

Table-2: Antibacterial Activity of the Test Compound 5a

\begin{tabular}{c|c|c|c|c|c}
\hline & $25 \mu \mathrm{M}$ & $50 \mu \mathrm{M}$ & $75 \mu \mathrm{M}$ & $100 \mu \mathrm{M}$ & $125 \mu \mathrm{M}$ \\
\hline E. coli & $0.00 \pm 0.00$ & $00.00 \pm 0.00$ & $0.67 \pm 0.58$ & $0.90 \pm 0.00$ & $1367 \pm 0.58$ \\
\hline S. typhi & $00.00 \pm 0.00$ & $0.70 \pm 1.00$ & $1.443 \pm 0.057$ & $1.67 \pm 0.58$ & $1.97 \pm 0.58$ \\
\hline C.albicans & $0.00 \pm 0.00$ & $0.00 \pm 0.00$ & $00.00 \pm 0.00$ & $0.67 \pm 0.115$ & $0.93 \pm 0.057$ \\
\hline S. aureus & $00.00 \pm 00$ & $0.00 \pm 0.00$ & $0.60 \pm 0.16$ & $1.00 \pm 0.10$ & $1.67 \pm 0.58$ \\
\hline Klebsiella & $0.67 \pm 0.58$ & $0.7 \pm 0.05$ & $1.47 \pm 0.05$ & $1.7 \pm 0.00$ & $2.33 \pm 0.15$ \\
\hline
\end{tabular}

Table-3: Antibacterial activity of the test compound 5c

\begin{tabular}{c|c|c|c|c|c}
\hline & $25 \mu \mathrm{M}$ & $50 \mu \mathrm{M}$ & $75 \mu \mathrm{M}$ & $100 \mu \mathrm{M}$ & $125 \mu \mathrm{M}$ \\
\hline E. coli & $0.60 \pm 0.00$ & $08.00 \pm 0.05$ & $1.3 \pm 0.10$ & $1.40 \pm 0.05$ & $1.6 \pm 0.58$ \\
\hline S. typhi & $00.64 \pm 0.11$ & $1.2 \pm 1.00$ & $1.8 \pm 0.057$ & $2.00 . \pm 0.58$ & $3.00 \pm 0.58$ \\
\hline C.albicans & $0.00 \pm 0.00$ & $0.00 \pm 0.00$ & $00.80 \pm 0.10$ & $1.00 \pm 0.115$ & $1.10 \pm 0.057$ \\
\hline S. aureus & $1.00 \pm 0.00$ & $1.40 \pm 0.05$ & $2.00 \pm 0.152$ & $3.20 \pm 0.057$ & $3.47 \pm 0.58$ \\
\hline Klebsiella & $0.67 \pm 0.11$ & $1.2 \pm 0.05$ & $1.87 \pm 0.152$ & $2.0 \pm 0.00$ & $3.00 \pm 0.115$ \\
\hline
\end{tabular}


RASĀYAN J. Chem.

Vol. 11 | No. 1 |175-180 | January - March | 2018

Table-4: Antibacterial activity of the test compound 5d

\begin{tabular}{c|c|c|c|c|c}
\hline & $25 \mu \mathrm{M}$ & $50 \mu \mathrm{M}$ & $75 \mu \mathrm{M}$ & $100 \mu \mathrm{M}$ & $125 \mu \mathrm{M}$ \\
\hline E. coli & $0.80 \pm 0.10$ & $1.00 \pm 0.58$ & $1.2 \pm 1.11$ & $1.40 \pm 0.00$ & $1.8 \pm 0.05$ \\
\hline S. typhi & $00.0 \pm 0.0$ & $00.0 \pm 0.0$ & $0.0 \pm 0.00$ & $0.70 . \pm 1.00$ & $1.00 \pm 0.10$ \\
\hline C.albicans & $0.00 \pm 0.00$ & $0.00 \pm 0.00$ & $00.00 \pm 0.10$ & $0.00 \pm 0.00$ & $0.00 \pm 0.00$ \\
\hline S. aureus & $0.00 \pm 0.00$ & $0.00 \pm 0.00$ & $0.00 \pm 0.00$ & $0.00 \pm 0.00$ & $0.00 \pm 0.00$ \\
\hline Klebsiella & $0.00 \pm 0.00$ & $0.0 \pm 0.00$ & $0.0 \pm 0.00$ & $0.7 \pm 0.11$ & $0.7 \pm 0.115$ \\
\hline
\end{tabular}

Table-5: Antibacterial activity of the test compound 5e

\begin{tabular}{c|c|c|c|c|c}
\hline & $25 \mu \mathrm{M}$ & $50 \mu \mathrm{M}$ & $75 \mu \mathrm{M}$ & $100 \mu \mathrm{M}$ & $125 \mu \mathrm{M}$ \\
\hline E. coli & $0.00 \pm 0.00$ & $0.60 \pm 0.10$ & $0.8 \pm 0.05$ & $1.20 \pm 0.115$ & $1.4 \pm 0.58$ \\
\hline S. typhi & $00.64 \pm 0.58$ & $1.2 \pm 0.58$ & $1.4 \pm 0.057$ & $1.80 . \pm 0.11$ & $2.00 \pm 0.10$ \\
\hline C.albicans & $0.00 \pm 0.00$ & $1.00 \pm 0.11$ & $1.60 \pm 0.15$ & $1.80 \pm 0.15$ & $1.80 \pm 0.057$ \\
\hline S. aureus & $0.60 \pm 0.00$ & $1.00 \pm 0.05$ & $1.60 \pm 0.10$ & $2.00 \pm 0.057$ & $3.00 \pm 0.057$ \\
\hline Klebsiella & $0.00 \pm 0.00$ & $0.6 \pm 0.05$ & $0.8 \pm 0.10$ & $1.2 \pm 0.00$ & $1.40 \pm 0.057$ \\
\hline
\end{tabular}

Table-6: Antibacterial activity of the test compound $5 \mathrm{~h}$

\begin{tabular}{c|c|c|c|c|c}
\hline & $25 \mu \mathrm{M}$ & $50 \mu \mathrm{M}$ & $75 \mu \mathrm{M}$ & $100 \mu \mathrm{M}$ & $125 \mu \mathrm{M}$ \\
\hline E. coli & $0.80 \pm 0.00$ & $1.2 .00 \pm 0.05$ & $1.6 \pm 0.10$ & $1.80 \pm 0.05$ & $2.40 \pm 0.58$ \\
\hline S. typhi & $1.04 \pm 0.11$ & $1.4 \pm 0.10$ & $1.6 \pm 0.057$ & $1.80 . \pm 0.10$ & $2.40 \pm 0.11$ \\
\hline C.albicans & $0.00 \pm 0.00$ & $0.60 \pm 0.10$ & $00.60 \pm 0.10$ & $0.60 \pm 0.115$ & $0.60 \pm 0.05$ \\
\hline S. aureus & $1.00 \pm 0.00$ & $1.60 \pm 0.1$ & $1.80 \pm 0.00$ & $2.00 \pm 0.00$ & $3.00 \pm 0.00$ \\
\hline Klebsiella & $3.00 \pm 0.11$ & $2.4 \pm 0.05$ & $3.0 \pm 0.152$ & $0.60 \pm 0.00$ & $2.40 \pm 0.00$ \\
\hline
\end{tabular}

Tested compounds<smiles>NC(CO)Cc1ccccc1</smiles>

$5 a$<smiles>Cc1ccc(CC(N)CO)cc1</smiles>

5c<smiles>CC(C)c1ccc(CC(N)CO)cc1</smiles><smiles>CCc1ccc(CC(N)CO)cc1</smiles><smiles>NC(CO)Cc1ccc2c(c1)OCO2</smiles>

$5 h$

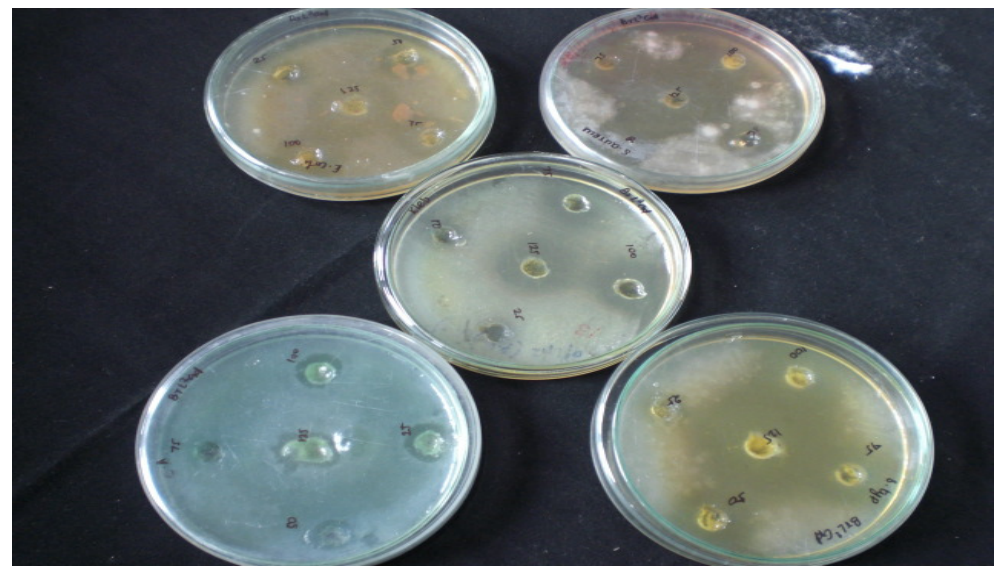

Fig.-3: Tested compound 5a 


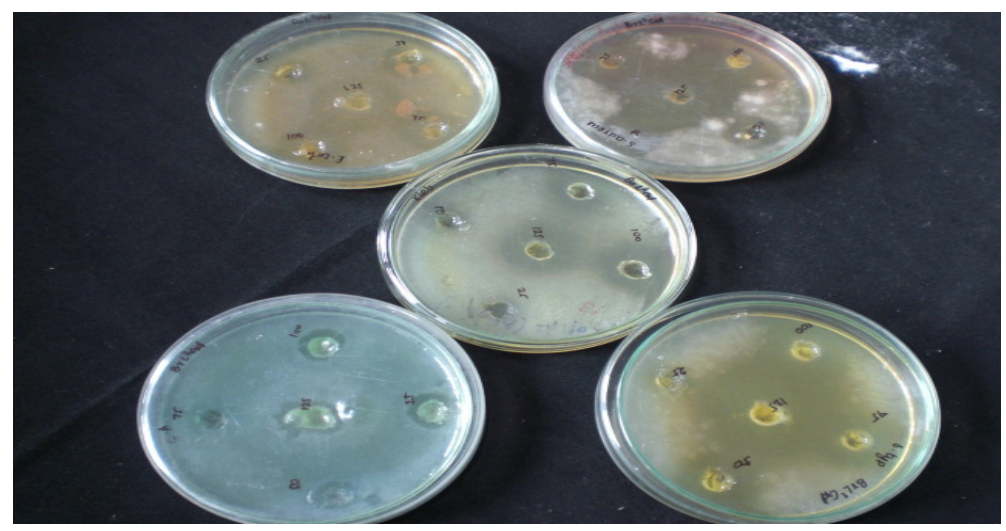

Fig.-4: Tested compound 5e

\section{CONCLUSION}

In conclusion, simply synthesized a novel class 2-amino-3-phenylpropane-1-ol by carbon nanotube method reaction for the first time. We have also carried nitro alcohol to amine compounds from iron and acidic acid reduction reaction method. Baylis-Hillman adducts to synthesize from a nitroolefin derivatives reaction with good yields. This reaction carried out lifetime kinetic and Biological Studies.

\section{ACKNOWLEDGEMENT}

We thank AMET University for the financial support. We also thank the university of Madras for the NMR facility and Indian Institute of Technology, Chennai for IR, and Mass Spectra.

\section{REFERENCES}

1. V. Declerck, J. Martinez and F. Lamaty, Chem. Rev., 109, 1, (2009).

2. V. Singh and S. Batra. Tetrahedron., 64, 4511, (2008).

3. D. Basavaiah, A.J. Rao and T. Satyanarayana, Chem. Rev., 103,811 (2003).

4. E. Ciganek, In Organic Reactions; L.A. Paquette, Ed; New York:Wiley., 51, 201. (1997).

5. D. Basavaiah, P.D Rao, and R.S. Hyma, Tetrahedron., 52, 8001, (1996).

6. W. Guo, W. Wu, N. Fan, Z. Wu, and C. Xia, Synth. Commun., 35, 1239, (2005).

7. Z. Wu, G. Zhou, J. Zhou, and W. Guo, Synth. Commun., 36, 2491, (2006).

8. S. Karur, J. Hardin, and A. Headley and G. Li, Tetrahedron Lett., 44, 2991 (2003).

9. D. Basavaiah and A. J. Rao, Tetrahedron Lett., 44,4365 (2003).

10. J. Vesely, R. Rios and A. Cordova, Tetrahedron Lett., 49, 1137 (2008).

11. R. Sengodan, R. Ranjithkumar, K. Selvam and B. Chandarshekar, Rasayan J. Chem., 11, 68 (2017).

12. S. Purwantiningsih, A. Salsabila, I. Auliya and A. Budi, Rasayan J. Chem., 10(3),175 (2017).

13. H. Cao, T. Viera, and H. Alper, Org. Let., 13, 11, (2011).

14. S. Hemalatha and M. Makeswari, Rasayan J. Chem., 10(3),843 (2017).

15. Sunil Kumar and R. Bigan, Rasayan J. Chem., 10(3),934 (2017).

16. V. Calo, A. Nacci, L. Lopez and A. Napola, Tetrahedron Lett., 42, 4701,(2001).

17. B.A. Kulkarni and A. Ganesan, J.Com. Chem., 1, 373 (1999).

[RJC-1864/2018] 